\title{
Reporting and Investigation of Unmanned Aircraft Systems (UAS) Accidents and Serious Incidents. Regulatory Perspective
}

\author{
Piotr Jan Kasprzyk ${ }^{1}$ (D) Anna Konert ${ }^{2}$ (D)
}

Received: 27 April 2020 / Accepted: 29 June 2021 / Published online: 3 August 2021

(C) The Author(s) 2021

\begin{abstract}
Naturally, the ever-growing number of drone operations conducted worldwide carries with it an increase in the number of safetyrelated incidents and occurrences. The reporting and subsequent investigation of unmanned aircraft system (UAS) accidents and serious incidents seems like a proven solution towards improving operational safety. Such procedures also stem from the fact that UAS are of recognized as aircraft - and aircraft accidents and serious incidents are subject to obligatory investigation. From a technical perspective, a key issue concerns discrepancies in the investigation process as there are significant differences between manned and unmanned aviation operations. From a regulatory perspective, one key question is to what extent should it be obligatory to conduct independent technical investigation of occurrences involving UAS? Such occurrences are not only accidents and serious incidents that involve both UAS and manned aircraft, where "traditional" rules of conducting a full and independent technical investigation apply - the majority occurrences involve only UAS that were either destroyed, damaged or acted as a hazard to third parties. The method of study comprised of content analysis of existing legislation. Current doctrines were confronted with existing regulations, documents, materials, safety reports and statistics. Results of the study shows that the extension of regulations created for manned aviation accident reporting and investigation may not be enough, and certain improvements are necessary, e.g. to standardize the reporting of occurrences and the criteria to conduct a formal accidents and serious incidents investigation. It is also reasonable to take actions aimed at raising awareness among UAS users of the need to report accidents and serious incidents, as well as engage them in the investigative process. The lack of standardization in this field has resulted in the lack of data that is "good enough" to indicate the main causes and factors that contribute to UAS accidents.
\end{abstract}

Keywords Unmanned aircraft systems · UAS · Drones · Aviation accidents · Serious incidents · Accident and serious incident investigation $\cdot$ ICAO annex $13 \cdot$ EU regulation 996/2010

\section{Introduction}

The global drone market has been showing steady, increased growth year after year. Meanwhile, the number of drone operations and the number safety-related occurrences involving

Anna Konert

a.konert@lazarski.edu.pl

Piotr Jan Kasprzyk

piotr.kasprzyk@lazarski.pl

1 Institute of Air and Space Law, Lazarski University in Warsaw, Warsaw, Poland

2 Faculty of Law and Administration, Lazarski University in Warsaw, Warsaw, Poland them, including accidents and incidents, has also been rising sharply [1].

These issues include air proximity incidents involving UAS reported by manned aircraft crews [2] and also mid-air collisions between manned aircraft and UAS. [3] There are also accidents resulting in damage or destruction of UAS which did not involve manned aircraft.

The principles of aviation accident investigation developed over the past decades remain virtually unchanged. The aim of the article is to analyze existing regulations, statistics and final reports concerning aviation accidents and serious incidents involving UAS. Occurrences other than accidents or serious incidents are beyond the scope of this paper [4]. From a safety perspective, reporting and investigating aviation accidents and serious accidents and reporting and analyzing safety-related occurrences are closely related. But remain subject to different legal regulations. The former is a reactive way of improving 
aviation safety through a thorough investigation of an accident or serious incident to prevent the repetition of similar situations in the future. The latter is a more proactive method that allows organizations and authorities to identify hazards and manage safety risks through the collection and analysis of various occurrences, not just those classified as an accident or serious incident.

\section{Discussion on International Regulations}

Regulations concerning the investigation of aviation accidents are an important element of the aviation safety regulatory framework and are aimed solely at improving aviation safety. One of the fundamental obligations stemming from art. 26 of the Chicago Convention is the obligation of a State of Occurrence to "institute an inquiry into the circumstances of the accident" ... "in the event of an accident to the aircraft". International standards and recommendations for the investigation of aviation accidents and serious incidents are included in Annex 13 to the Chicago Convention. The sole purpose of such an investigation is to prevent accidents (Point 3.1. of Annex 13). It is to be done by gathering and analyzing information, drawing conclusions, including the determination of causes and - when appropriate - the making of safety recommendation [5]. Under Annex 13, the aviation accident investigation process is designed to ensure that the causes of an accident be determined by an independent and competent public (state) authority.

In 2010, by adopting the 10th edition of Annex 13, it was decided that the standards and recommended practices of Annex 13 should also apply to accidents and serious incidents involving UAS. As a consequence, the definition of aviation accident was revised. Is should be stressed that this definition is key to assessing whether an investigation should be instituted and conducted.

An aviation accident is an occurrence associated with the operation of an aircraft which results in death or serious injury, substantial damage to the aircraft, or its disappearance. However, for an occurrence to be considered an aviation accident subject to reporting and investigation - in the case of manned aircraft - it must take place between the time any person boards the aircraft with the intention of flight until the time when all such persons have disembarked. In the case of a UAS, an accident should be considered as an occurrence which takes place between the time the aircraft is ready to move with the purpose of flight until such time as it comes to rest at the end of the flight and the primary propulsion system is shut down.

Despite these differences, the definition of aviation incident has remained unchanged. An incident is defined as an occurrence associated with the operation of an aircraft, other than an accident, which affects or could affect its safety of operation.
If, nevertheless, the circumstances of the incident indicate that it was nearly an accident, it is considered a serious incident" and is subject to mandatory investigation. Annex 13 limits the obligation to investigate serious incidents to aircraft with a maximum take-off mass of over $2.250 \mathrm{~kg}$ (5.1.2).

Pursuant to Annex 13, the occurrence of an aviation accident or a serious incident should result in a technical investigation conducted by an independent state authority (independent from judicial authorities and independent from any civil aviation authority or its equivalent). However, as far as UAS are concerned, the provisions of Annex 13 stipulate that the obligation to investigate accidents and serious incidents involving them should only apply to those with a design and/ or operational approval (Note 3 in item 5.1 of Annex 13.).

Therefore, in accordance with Annex 13, accidents and serious incidents involving UAS should be investigated in situations where UAS operations caused or contributed to the occurrence of a accident or serious incident involving manned aircraft - in other words, an aviation accident (or serious incident) involving a manned aircraft which resulted from the presence of an unmanned aircraft e.g. a collision between a manned aircraft and a UAS which results in an accident of said manned aircraft. Similarly, a serious incident involving a manned aircraft and UAS will be subject to mandatory investigation if its circumstances indicate a high probability of a manned aircraft accident.

However, if an accident involves only UAS, i.e. if the UAS operation (flight) resulted in death, serious injury or if a UAS was substantially damaged or disappeared, then the accident should be investigated if:

- the UAS had an approved design; and / or

- operational approval for said UAS operation was issued.

Ultimately, determining the legal obligation to whether to launch an investigation into an accident or serious incident exclusively UAS is up to a Contracting State and is decided in regulations implementing the standards of Annex 13 to its national law. Solutions adopted in the EU and US are presented below.

- In addition to making general recommendations regarding the investigation of UAS accidents, ICAO advisory materials also indicate quite significant issues requiring further analyses, necessary to support research processes related to UAS accident investigation [6]. The most important include the need to ensure that: (1) data on UAS operations are recorded and the requirements in this respect should be adapted to the type of UAS and its operation; (2) possible loss of communications with a UAS does not cause loss of such data; (3) a UAS transmits its position within a radius of at least $6 \mathrm{NM}$ for the purpose of its location in the event of an accident (or 
disappearance). More detailed recommendations related to the UAS accident the aircraft of a maximum gross takeoff weight of 300 pounds (about $136 \mathrm{~kg}$ ) or greater sustains substantial damage.

However, particular consequences in the form of injury or substantial damage to the aircraft were not defined, which means that the general definitions apply.

Consequently, the obligation to undertake investigation processes have been published by the International Society of Air Safety Investigators [7].

\section{Analysis of EU Regulations (EASA)}

At a European Union (EU) level, the standards and recommendations made in Annex 13 have been implemented in the provisions of EU Regulation 996/2010 [8].

The definition of accident and serious incident in Regulation 996/2010 is identical to that of Annex 13 and also applies to unmanned aircraft. Therefore, an accident is an occurrence associated with the operation of an aircraft which, in the case of an unmanned aircraft, takes place between the time the aircraft is ready to move with the purpose of flight until such time as it comes to rest at the end of the flight and the primary propulsion system is shut down, in which a person is fatally or seriously injured or the aircraft sustains substantial damage or destruction or is missing.

Regulation 996/2010 also defines a serious incident based on the provisions of Annex 13. A serious incident is an incident involving circumstances indicating that there was a high probability of an accident and is associated with the operation of an aircraft, which in the case of an unmanned aircraft, takes place between the time the aircraft is ready to move with the purpose of flight until such time as it comes to rest at the end of the flight and the primary propulsion system is shut down. A list of examples of serious incidents is set out in the Annex and relate to, for example:

- near collisions in the air;

- near collisions with the ground;

- aircraft or engine structural failures not classified as accidents.

Between the years 2010-2018, EU Regulation 996/2010 had limited applications to UAS operations.

Only those UAS-related occurrences that resulted in an accident or a serious incident to a manned aircraft were subject to investigation.

The decision to institute an accident or serious incident investigation involving exclusively UAS was left at the discretion of the safety investigation authority. This was due to the EU lacking competencies over unmanned aircraft other than those with a take-off mass of over $150 \mathrm{~kg}$ [9].

EU Regulation 996/2010 establishing uniform principles for the investigation of accidents and serious incidents is closely linked to so-called the Basic Regulation (EU Regulation 216/2008) [10], which lays down uniform rules for civil aviation safety. Until 2018, the Basic Regulation only gave the EU regulatory competencies over drones heavier than $150 \mathrm{~kg}$.

Therefore, as a general rule, Member States were not required to investigate accidents which exclusively involved UAS lighter than $150 \mathrm{~kg}$, even if such an accident resulted in death or serious injury [11]. Nevertheless, Member States (their respective safety investigation authorities) could decide to conduct such an investigation, which had its legal basis in art. 5 paragraph 4 of EU Regulation 996/2010.

With the extension of EU competencies to all unmanned aircraft, which took place when the new Basic Regulation (EU Regulation 2018/1139) [12] entered into force, it was necessary to change the provisions of the Regulation (EU) 996/ 2010 regarding the reporting and investigation of accidents involving UAS.

The European Network of Civil Aviation Safety Investigation Authorities (ENCASIA) formulated an opinion back in 2015 to allow for greater flexibility when investigating accidents involving UAS and manned aircraft with a MTOW of less than $2250 \mathrm{~kg}$. This opinion was backed by claiming that safety investigation authorities across the EU have limited resources, and that their activities should be focused on maintaining the safety of the commercial aviation transportation system. [13]

Taking this into account, Regulation (EU) 2018/1139 amended art. 5 of Regulation (EU) 996/2010 and currently the rules for reporting and investigating accidents and serious incidents involving UAS are as follows:

Based on art. 9 item 1 and in connection with art. 2 item 11 of the Regulation 996/2010, every accident and serious incident involving UAS is subject to mandatory reporting to the safety investigation authority in the State of Occurrence by the "person involved." The term "person involved" includes the owner of the aircraft involved in the accident, its pilot and / or remote operator, any person involved in its design, manufacture, maintenance or the training of the UAS crew, as well as any aviation authority staff.

However, reporting an accident or a serious incident involving UAS does not mean that it will be investigated by the safety investigation authority, as the obligation to undertake an investigation depends on several factors. Generally speaking, UAS-related accidents may be split into two groups:

1) where UAS involvement resulted in an accident or serious incident of a manned aircraft - general rules for conducting a safety investigation apply. 
2) where only UAS were involved and their operations resulted in an accident or serious incident.

The obligation to conduct a technical investigation into accidents falling into the latter group has been limited to the following cases indicated in art. 5 paragraph 5 of Regulation (EU) 996/2010 as amended by Regulation (EU) 2018/1139:

- a person was fatally or seriously injured as a result of the occurrence; or

- the UAS involved was manufactured in accordance with the certificate or declaration of the manufacturing organization, in accordance with the applicable implementing or delegated regulations related to UAS issued on the basis of the Regulation (EU) 2018/1139.

It should be noted that the EC Delegated Regulation 2019/945 [12, 14] published in 2019 does not allow for UAS design or production based on a declaration from the manufacturing organization. However, under general rules of initial airworthiness, it is possible to apply to the European Union Aviation Safety Agency (EASA) for UAS certification. To facilitate such processes, EASA published socalled "special conditions" [15] for light UAS in December 2020 that are applicable to UAS with a MTOM of up to 600 $\mathrm{kg}$ and which are not intended to be used to transport people, or operated in the specific or certified category of operations under Implementing Regulation (EU) 2019/947 [16]. Therefore, it is possible that the very first UAS will be subject to certification under EASA in the near future. Accidents or serious incidents of certified UAS will be subject to obligatory safety investigations.

Summing up, an obligatory investigation into an accident or serious incident involving a UAS under Regulation (EU) 996/2010 is limited to those UAS that will be certified by EASA. Other accidents involving UAS are subject to mandatory investigations only when fatalities, serious injuries or manned aviation operations were involved.

Any other accident or serious incident involving a UAS (e.g. when a non-certified UAS is destroyed or substantially damaged) may become subject to an investigation if the competent authority decides to do so, taking any lessons learned as a contribution to increasing aviation safety as a whole. This decision is left at the discretion of an individual state's safety investigation authority and will likely be taken ad hoc, during an initial evaluation of a reported accident or serious incident.

It is also possible to adopt a more systemic approach. For example, the general policy adopted in the UK can be found in the Aviation Safety Report for 2018 [17]. The Air Accidents Investigation Branch AAIB will investigate a UAS accident if it was being operated under permission from the Civil Aviation Authority or if the UAS had a take-off weight greater than $20 \mathrm{~kg}$ (airworthiness approval is required for such operations). However, a field investigation will only be conducted if the UAS accident resulted in a fatality. In other cases, the AAIB will collect data from the remote pilot involved, and an investigation will only be carried out if there was a serious injury or any other significant safety issue appears [17].

\section{Analysis of US Regulations}

In the USA, regulations on aviation accident and serious incident investigations can also be split into two situations. If an occurrence involving a UAS resulted in an accident or serious incident that also involved a manned aircraft, then he general rules for conducting an investigation apply. However, the investigation of accidents and serious incidents involving solely UAS are subject to a different set of dedicated rules which were adopted in 2010 as a result of a proposal from 2008 by the National Safety Transportation Board (NTSB) [18].

Firstly, all UAS classified as models within the meaning of the FAA Modernization and Reform Act 2012 are excluded from the provisions on the reporting and investigation of accidents and serious incidents.

Secondly, a definition of an unmanned aircraft accident which is subject to a mandatory investigation by the NSTB was introduced - it constitutes an occurrence associated with the operation of a UAS that takes place between the time that the system is activated with the purpose of flight and the time that the system is deactivated at the conclusion of its mission, in which:

- $\quad$ any person suffers death or serious injury; or

- an aircraft with a maximum gross take-off weight of 300

lbs. (app. $136 \mathrm{~kg}$ ) or greater sustains substantial damage.

Definitions of serious injury or substantial damage to the aircraft are the same for manned and unmanned aircraft accidents.

Consequently, the obligation to investigate an accident involving a UAS arises when it resulted in death or an injury, regardless of what the UAS weighed. However, in the case of substantial damage to UAS, an investigation will only be launched for heavy UAS models.

On the one hand, a definition for UAS accident was introduced with the intent of confirming that the investigation of such accidents falls within the competence of the NTSB. On the other, it was necessary to limit the obligation to investigate such accidents to only the most serious cases - hence the weight threshold. One such example includes the accident to the experimental UAS Titan Solara 50. [19]

Thirdly, the obligation to notify the NTSB of serious incidents involving UAS was extended upon their operators. The obligation to report serious incidents is independent of a UAS take-off weight. This means that UAS operators are not only 
obliged to report UAS accidents that are subject to investigation by the NTSB, but also to report on serious incidents.

Serious incidents identified in PART 830 include the following examples and - if they apply to UAS - are subject to obligatory notification of the NTSB:

- malfunction or loss of control of the aircraft;

- damage to property exceeding 25,000 USD (other than aircraft damage costs);

- detachment of all or a portion of a propeller or rotor blade.

The obligation for UAS operators to report serious incidents to the NTSB (irrespective of UAS weight) is associated with the regulatory body's right to decide on whether to investigate any serious incident [20].

The NTSB also has the right to investigate occurrences other than accidents or serious incidents involving UAS within the meaning of PART 830. This applies in particular to incidents, i.e. occurrences which affect or could affect the safety of aviation operations.

The obligation to report UAS accidents and serious incidents to the NTSB is separate from the obligation to report specific events involving UAS directly to the Federal Aviation Administration (FAA), which results from the provisions on UAS operations (PART 107, §107.9). According to this provision, no later than 10 days after the occurrence, a UAS pilot is obliged to report to the nearest FAA regional branch any occurrences related to a UAS operation that involved at least:

- serious injury to any person or loss of consciousness;

- damage to property exceeding USD 500 (other than damage to the UAS).

The obligation to report any of the above occurrences to the FAA results from the need to provide said authority with information on possible sources of hazards and is parallel and complementary to reporting accidents to the NTSB [2].

Sources indicate that in between 2010 and 2017, only five UAS accidents were reported and which were the subject of subsequent investigation by the NTSB [2]. All of these solely involved UAS.

\section{Discussion on the Investigation of Accidents Involving UAS}

Accident investigation authorities have already published final reports on accidents or serious incidents involving UAS, and certain statistics have also been made available. Nevertheless, when comparing the available data, it should be remembered that there are no harmonized rules on when to report and investigate an accident or serious incident involving a UAS. Despite various programs established to collect data on such occurrences, the sharing of data and the standardization of accident reporting and investigation processes are still in their primary stages of maturity $[1,21]$.

The largest number of final reports on UAS accident investigations are made available by the UK AAIB, and a respective summary is provided in the regulator's Annual Safety Review 2018 [17]. According to this report, 36 accidents involving UAS were reported in the period 2015-2018. Most of these occurred due to technical issues, mainly loss of control of a UAS.

According to the AAIB Bulletin 1/202 [22] in the period between February 2015 and July 31, 2019, the total number of accidents reported to AAIB was 59 .

Final reports released by the UK AAIB on accidents involving UAS lead to the conclusion that the investigation of such accidents may help increase overall levels of safety. The causes of accidents determined through investigations include technical issues, software errors, organizational issues, flight preparation errors and meteorological conditions. Interestingly, out of the 59 reported accidents, 18 involved one particular UAS model.

Conclusions drawn from the available final reports can be used in the process of acquiring or upgrading qualifications of UAS operators or pilots. One might also use them in the process of preparing safety analyses.

As the AAIB indicates in its Annual Safety Review 2018 [17], the investigation of accidents involving small UAS allows, among others, to raise levels of relevant knowledge on UAS by safety investigation experts; identify trends that may affect regulations or operator training; inform manufacturers about potential design issues; issue safety recommendations; and raise overall awareness.

Final reports from other countries on UAS accidents are also available.

For example, a final report by the Belgian AAI [23] describes the following accident. A UAS was used to perform a flight in a zone separated from controlled airspace, however after take-off, a series of communications interruptions with the UAS occurred, and despite the operator having activated the drone's automatic landing system, the UAS discontinued its approach for landing, changed its heading and flew for 110 NM. It finally ended its flight by crashing over French territory. It's important that this particular UAS was equipped with a transponder, which enabled air traffic services to separate other air traffic from its course, particularly when it was flying through controlled airspace. Following an investigation, a software error was deemed as the direct cause of the accident, allowing the UAS to abort the forced landing procedure initiated after loss of communications. This event was classified as an accident due to the destruction of the UAS.

A similar occurrence took place in Poland, although it involved a UAS operated by the military. During a military training exercise, a loss of communications occurred with 
the UAV and, as a result the, aircraft left the zone that had been designated for military exercises. Similarly in this case, the failsafe system did not work, which resulted in the UAS continuing with its flight. The drone flew for app. $75 \mathrm{~km}$ before it fell into a forest. Since the UAS was used in a military operation, the occurrence itself was not subject to investigation by the PKBWL (State Commission on Aircraft Accidents Investigation). However, the occurrence was qualified as an incident [24] and an investigation into its circumstances (due to the fact that they constituted a hazard to air traffic) was carried out by the Polish Air Navigation Services Agency, under the supervision of PKBWL. Apart from trying to identify what caused the loss of communications, the investigation also aimed at establishing how air traffic services should react in situations where a UAS leaves a designated training zone.

The investigation was followed by preventive recommendations which indicated the need to develop procedures for air traffic services that would determine how to deal with similar situations in the future. The described occurrence was classified as an incident, probably due to the fact that - as indicated in the investigation report - it was possible to determine the direction of the UAS flight and thus limit the area of the stray UAS being a possible hazard to air traffic. In the end, this situation was assessed as more of a fortunate coincidence than as a rule, since loss of control over a UAS usually also results in loss of traceability over its flight parameters.

Another report published by the PKBWL covers a UAS accident that occurred in 2019 during an examination flight for a UAS remote pilot rating. The UAS used for said flight was damaged and a series of technical and operational problems occurred when another UAS was used to continue the examination process. They resulted in the UAS starting its propulsion system right after stand-by mode was activated. As a consequence, the pilot being examined was seriously injured by the UAS's blades [25] PKBWL was unable to determine why the UAS started its engines when in stand-by mode, but issued safety recommendations related to this particular UAS model's technical manual.

It has to be noted that, based on the available final reports from investigation into UAS accidents and serious incidents, EASA indicated in its Annual Safety Review for 2017 a few basic concerns related to UAS safety. These are [26]:

- Aircraft upset caused by loss of control;

- Risk of collision in the air;

- Risk of collision with an obstacle on the ground.

It is important that both EASA and AAIB analyses show that the main causes of the investigated accidents involving UAS were technical failures.

According to EASA data from 2017, out of 32 UAS accidents reported between 2012 and 2016, 16 were caused by aircraft upset.
According to UK AAIB data from 2019, out of 59 UAS accidents reported between 2015 and 2019, 37 were caused by technical failures.

The above statistics are also confirmed by available scientific research. An analysis of over 150 publicly available reports on accidents and incidents involving civilian UAS (data from the USA and Australia for the period 2006-2015) shows that $61 \%$ of occurrences were caused by technical failures of one of the elements of a UAS (i.e. System Component Failure) $[21,27]$. The analysis pointed out that human error was less of a causal factor than electromechanical failure. However, the conclusions from this analysis indicate that the available data on occurrences involving UAS are nonhomogenous [1, 21, 27].

UAS accidents are raising a number of safety and social concerns which have to be addressed by aviation safety regulators when developing operational rules for UAS. A good example of how safety regulators react to new occurrences and accidents is EASA's recent decision to amend already adopted EU law for drone operations, although implementing rules for drones operations were not in force at the time [16].

In 2019, two accidents occurred in Switzerland during a project that aimed to use UAS to transport blood samples between hospitals. In February 2019, a drone crashed into a lake while transporting blood samples from a hospital to a laboratory. Due to a technical failure of the UAS's GPS receiver and other components, the drone could no longer determine its own position and initiated an emergency landing by switching off its engines and deploying an emergency parachute [28]. Later that year, another accident occurred. Around 2 min after take-off, a UAS's flight termination system was automatically activated, initiating an emergency landing procedure. After a parachute was deployed, its connecting line with the UAS broke and the drone hit the ground after an uncontrolled descent in the vicinity of a preschool. The UAS was destroyed and nobody was injured. Two investigations have been launched into the matter. One is being conducted by the STSB (Switzerland's safety investigation authority) [29], and the other was initiated by the owner of the project and the drone operator, and is being conducted by the independent aviation experts [30]. Based on the results of the investigations, the operation has been restarted. Since both accidents gave rise to considerable safety and societal concerns, EASA decided to propose an amendment to drone regulation that were already published and about to enter into force. With NPA 2020-07, EASA proposed to clarify the conditions under which UAS beyond visual line of sight (BVLOS) operations over a populated area or an assembly of people can be authorized in the specific category. This proposal was adopted on December 17, 2020, a few days before the new EU drone regulations came into force [16]. 


\section{Conclusions. Results of the Study}

An analysis of applicable regulations, reports and statistics on investigations conducted into accidents and serious incidents involving UAS leads to the following conclusions.

Applicable regulations on accident and serious incident reporting and investigation in civil aviation were designed and developed for manned aviation.

The recognition of UAS as aircraft led to the recognition of an accident or a serious incident involving UAS as an occurrence that requires reporting to regulators and, if certain conditions are met, an investigation to identify its causes. However, due to fundamental differences between manned and unmanned aircraft operations, at least two aspects are important when carrying out accident investigations that involve UAS. Firstly, safety accident investigation authorities need have a better understanding of the differences between the two $[1,2,7]$. Secondly, some aspects of accident investigation process must be improved or developed to reflect these differences $[1,2,6]$.

From a regulatory perspective, one of the key aspects lies in determining which accidents and serious incidents involving UAS should be subject to an investigation. This requires taking a balanced approach, so as not to apply costly and timeconsuming investigative procedures (developed for manned aviation) to cases that do not require them. In light of this, the resources and attention of safety investigation authorities are directed at investigating accidents and serious incidents that resulted in a collision or a near miss between a UAS and a manned aircraft. Particular attention is required for serious incidents in which pilots report a potential collision with a UAS, but only a detailed investigation can verify that no other object was involved, e.g. a bird (a so-called false positive). Even in this area of investigations, it seems necessary to develop a dedicated methodology [2].

With the ongoing development of the UAS sector, more attention is being paid to accidents solely involving UAS. As mentioned earlier, due to the fact that investigation authorities have limited resources, and because of the high costs of investigative activities, investigations into such occurrences are mostly undertaken in cases involving more complex UAS models, or when the occurrence resulted in fatal or serious injury. In other cases, the decision to investigate such accidents is left at the discretion and assessment of an individual state's authorities.

Another important issue is raising awareness among UAS users about their obligation to report accidents and serious incidents. Available statistics indicate that a significant number of accidents and serious incidents involving UAS are never reported. This seems to stem from a low legal awareness among drone users. In the EU for example, reporting every accident involving UAS is mandatory - regardless of its mass or type of operation. Meanwhile, data for the years 2015-2018 shows that, on average, around 30-40 accidents were reported annually in the EU as a whole [4]. That means that some countries had no UAS accidents reported at all, and such reports are not included in official statistics, despite media reports to the contrary.

Changing this requires, as it did in manned aviation, a gradual building of trust between UAS users and the authorities responsible for aviation safety, combined with simultaneously raising levels of legal awareness among UAS users.

As a first step, states should adopt clear national "policies" for the investigation of UAS-related accidents and serious incidents and invite UAS users to participate in investigative processes. Some occurrences could be investigated by the operators themselves under supervision from state authorities. Such action would surely serve to raise the overall levels of safety of UAS operations, as well as lead to a better understanding of new UAS technology by regulators.

Finally, there is a much broader aspect to aviation accident and serious incident reporting and investigation regulations these regulation are part of the aviation safety regulation system which has been developed for more than a century. This system is now under revision as the challenges posed by unmanned aviation have to be addressed to allow that sector to develop. Regulations on UAS accident and serious incident reporting and investigation should also be discussed. Three key proposals are made for further analysis:

1) accidents and serious incidents solely involving UAS should be reported to the competent authority, irrespective of mass, category or type of operation. However, this requires an obligatory reporting systems for UAS accidents. Reporting such occurrences in the same way as manned aviation accidents is not a good solution. Rather than just expanding manned aviation accident reporting obligations to cover unmanned aviation, new schemes or systems must be developed instead. An interesting example is PART 107 and its requirements which oblige UAS pilots in the US to report clearly defined UAS safety occurrences to the nearest FAA regional branch (serious injury to a person or any loss of consciousness, damage to property - other than UAS damage - exceeding USD 500),

2) accidents and serious incidents involving both manned and unmanned aircraft should always be subject to a full investigation by aviation safety investigation authorities, irrespective of the MTOM of the aircraft involved. Midair or near collisions between manned and unmanned aircraft have already been reported and their investigations should always be conducted to prevent the reoccurrence of similar situations in the future,

3) when deciding that the investigation of accidents and serious incident involving exclusively UAS should stay within the scope of responsibilities of the aviation safety investigation authorities, politicians should also address the issue of limited resources, i.e. by discussing on budgets allocated to these authorities so that these take into 
consideration current aviation trends and the growing number of UAS operations.

Acknowledgements Research financed by the National Science Centre, Poland. Project No 2017/27 /B/HS5/0008 "Unmanned Aircraft. A New Era in Aviation Law",

Authors Contributions Piotr Kasprzyk - Sections 1,2,3,4,5,6. Anna Konert - sections 1,2,3,5,6,

Funding Article is the effect of a research grant financed by the National Science Centre, Poland. Project No 2017/27 /B/HS5/0008 "Unmanned Aircraft. A New Era in Aviation Law".

\section{Declarations}

Ethical Approval Not applicable’.

Consent to Participate Not applicable'.

Consent to Publish Not applicable'.

Competing Interests Not applicable'.

Open Access This article is licensed under a Creative Commons Attribution 4.0 International License, which permits use, sharing, adaptation, distribution and reproduction in any medium or format, as long as you give appropriate credit to the original author(s) and the source, provide a link to the Creative Commons licence, and indicate if changes were made. The images or other third party material in this article are included in the article's Creative Commons licence, unless indicated otherwise in a credit line to the material. If material is not included in the article's Creative Commons licence and your intended use is not permitted by statutory regulation or exceeds the permitted use, you will need to obtain permission directly from the copyright holder. To view a copy of this licence, visit http://creativecommons.org/licenses/by/4.0/.

\section{References}

1. Sánchez, S.M., Valdés, R.M.A., Comendador, F.G., CuernoRejado, C.: Unmanned vs manned Aircraft Systems accidents investigation: post-accident analysis, benchmarking and improvements. https://doi.org/10.13009/EUCASS2019-429

2. Guzzetti, J.: Why it Makes a Difference to Report and Investigate UAS Incidents Even When They Don't Really Happen, International Society of Air Safety Investigators Submission for the 2017 ISASI Seminar in San Diego, California

3. https://aviation-safety.net/database/issue/drones.php. Accessed: 15 April 2020

4. Kasprzyk, P, Konert, A.: Reporting UAS related incidents under aviation occurrence reporting legislation, 2020 International Conference on Unmanned Aircraft Systems (ICUAS), IEEE Xplore

5. Milde, M.: International Air Law and ICAO, p. 94

6. ICAO Doc.: 10019. Manual on Remotely Piloted Aircraft Systems (RPAS). 1st Edition, 2015

7. Unmanned Aircraft System Handbook and Accident/Incident Investigation Guidelines (International Society of Air Safety Investigators, 2015)
8. Regulation (EU) No $996 / 2010$ of the European Parliament and of the Council of 20 October 2010 on the investigation and prevention of accidents and incidents in civil aviation, Official Journal of the European Union L 295/35 of 12/11/2010 as amended

9. Konert, A, Kasprzyk, P.: Drones Are Flying outside of Segregated Airspace in Poland. New Rules for BVLOS UAS Operations, Journal of Intelligent and Robotic Systems (2020), Drones Are Flying outside of Segregated Airspace in Poland

10. Regulation (EC) No 216/2008 of the European Parliament and of the Council of 20 February 2008 on common rules in the field of civil aviation and establishing a European Aviation Safety Agency. Official Journal of the European Union L 79/1 of 19/03/2008

11. Support study to the evaluation of Regulation (EU) No 996/2010 on the Investigation and Prevention of Accidents and Incidents in. Civil Aviation. Final Report

12. Regulation (EU) 2018/1139 of the European Parliament and of the Council of 4 July 2018 on common rules in the field of civil aviation and establishing a European Union Aviation Safety Agency. Official Journal of the European Union L 212/1 of 22/08/2018

13. ENCASIA opinion dated 30.08.2015, https://ec.europa.eu/transport/ modes/air/encasia/activities/opinions en. Access 02.03.2021

14. Commission Delegated Regulation (EU) 2019/945 of 12 March 2019 on unmanned aircraft systems and on third-country operators of unmanned aircraft systems. Official Journal of the European Union L 152/1 of 11/06/2019

15. Special Conditions SC Light-UAS Medium Risk 01

16. Commission Implementing Regulation (EU) 2019/947 of 24 May 2019 on the rules and procedures for the operation of unmanned aircraft. Official Journal of the European Union L 152/45 of $11 / 06 / 2019$

17. Air Accidents Investigation Branch. Annual Safety Review 2018

18. PART 830-75 Fed. Reg. 51955, August 24, 2010

19. https://www.ntsb.gov/investigations/ layouts/ntsb.aviation/brief. aspx?ev_id=20150505X85410\& key=1. Access 05.03.2021

20. NTSB Advisory to Operators of Civil Unmanned Aircraft Systems in the United States, July 29th, 2017

21. Wild, G. et al.: A Post-Accident Analysis of Civil Remotely-Piloted Aircraft System Accidents and Incidents, J. Aerosp. Technol. Manag. 9(2), (2017)

22. https://www.gov.uk/aaib-reports/aaib-investigation-to-dji-matrice210-uas-registration-n-a-16-march-2019. Access 05.03.2021

23. https://mobilit.belgium.be/sites/default/files/downloads/accidents/ final_report_2016-aii-01.pdf. Access 05.03.2021

24. https://www.gov.pl/documents/905843/1047987/20160376RK. pdf. Access 05.03.2021

25. https://pkbwl.gov.pl/images/raporty/Raport Ko\%C5\%84cowy 4305_19.pdf. Access 05.03.2021

26. https://www.easa.europa.eu/document-library/generalpublications/annual-safety-review-2017. Access 05.03.2021

27. Wild, G., Murray, J., Baxter, G.: Exploring civil drone accidents and incidents to help prevent potential air disasters. Aerospace. 3(3), 22 (2016)

28. https://www.sust.admin.ch/inhalte/AV-berichte/SUI-9909_D.pdf. Access 15.03.2021

29. https://www.sust.admin.ch/inhalte/AV-berichte/ZB_SUI-9903.pdf. Access 15.03.2021

30. https://www.easa.europa.eu/document-library/agency-decisions/ ed-decision-2020022r. Access 15.03.2021

Publisher's Note Springer Nature remains neutral with regard to jurisdictional claims in published maps and institutional affiliations.

Piotr Kasprzyk Attorney at law, research fellow of the Institute of Air and Space Law at Lazarski University in Warsaw, Poland 
Milad Abolhasani Attorney at law, director of the Institute of Air and Space Law, director of Aviation Law and Professional Pilot Licence studies, Dean of the Faculty of Law and Administration at Lazarski University in Warsaw 